\title{
A Simple Gas Forge for Making Microneedles
}

\author{
By T. J. ELLIOTT AND L. A. DARBY \\ Glasshouse Crops Research Institute, Littlehampton, Sussex BNI6 ${ }_{3} P U$
}

(Received 5 April 1976)

\section{INTRODUCTION}

Microneedles are usually made from soda-glass rod, softened by heat and then drawn out. They can be made by hand but a forge is needed if many fine rapidly-tapering needles are required. Such forges need not be complex and expensive.

The principle of using the tension in an expanded coil spring to draw out the softened glass has been exploited in an earlier design (Thaysen \& Morris, 1947). The forge described below enables more precise control of this tension and incorporates other design improvements.

\section{METHODS}

The forge, depicted in Fig. I, is made from the following: aluminium alloy strip $380 \times 100 \times 12 \mathrm{~mm}$ for the base and $254 \times 19 \times 6 \mathrm{~mm}$ for the feet $(\mathrm{I}, 2)$; two $80 \mathrm{~mm}$ lengths of 2BA brass studding and knobs to fit (3); two $2 \mathrm{BA}$ brass nuts and locking washers (4); four size Io fishing-line swivels with links (5); two $20 \times 3 \mathrm{~mm}$ steel coil springs (6); two I $5 \times 9 \mathrm{~mm}$ diam. brass rods with $4 \mathrm{~mm}$ core drilled out (connectors) (7); two $10 \mathrm{~mm} 4 \mathrm{BA}$ nylon bolts (8); two $5 \mathrm{~mm}$ lengths of 6BA brass studding (pegs) (9); about $200 \mathrm{~mm} 0.7 \mathrm{~mm}$ spring steel wire (for retaining clips) (Io).

The alloy strip is cut to shape and the end lugs threaded $2 \mathrm{BA}$. The holes for the retaining clips, the peg guide-channels (II) and the V-groove (I2), in which the glass rod rests, are machined and the feet fitted. Each connector is drilled and tapped to take a $4 \mathrm{BA}$ nylon bolt which secures the glass rod, and a 6BA studding peg which is soldered into position.

The two tensioning units, each one comprising studding, two fishing-line swivels, spring and connector are assembled. A short length of wire through a small hole in the connector attaches it to one swivel, and one end of the $2 \mathrm{BA}$ studding is ground into a flat and drilled to fix the other swivel. The two tensioning units are mounted on the forge and the knobs attached. The spring wire clips which lightly hold the glass rod in the $\mathrm{V}$-groove and allow its easy insertion and removal are fitted to complete construction.

The pilot flame of a bunsen burner (13) provides the gentle heat needed for softening the glass.

The forge is designed to take $\mathrm{I} 80 \mathrm{~mm}$ lengths of $4 \mathrm{~mm}$ diam. glass rod; each piece makes two needles about $100 \mathrm{~mm}$ long. The glass rod is fixed in the forge by the spring clips and nylon bolts. Five to ten turns of each knob apply tension to the coil springs and so to the rod. Rotational forces are not transmitted to the glass rod because of the joint action of the swivels and the pegs. The rod is heat softened and is drawn out as the springs contract. The waist in the rod (I4) is kept central by adjusting both tensioners. As the rod becomes thinner, fewer turns and less heat are needed. In the final stages a part turn and the merest trace of heat are sufficient. The two needles are separated while cold by a further turn of the control knobs. The 'feel' of the tensioners can be changed to suit the operator by adjusting the locking nuts on the studding. 


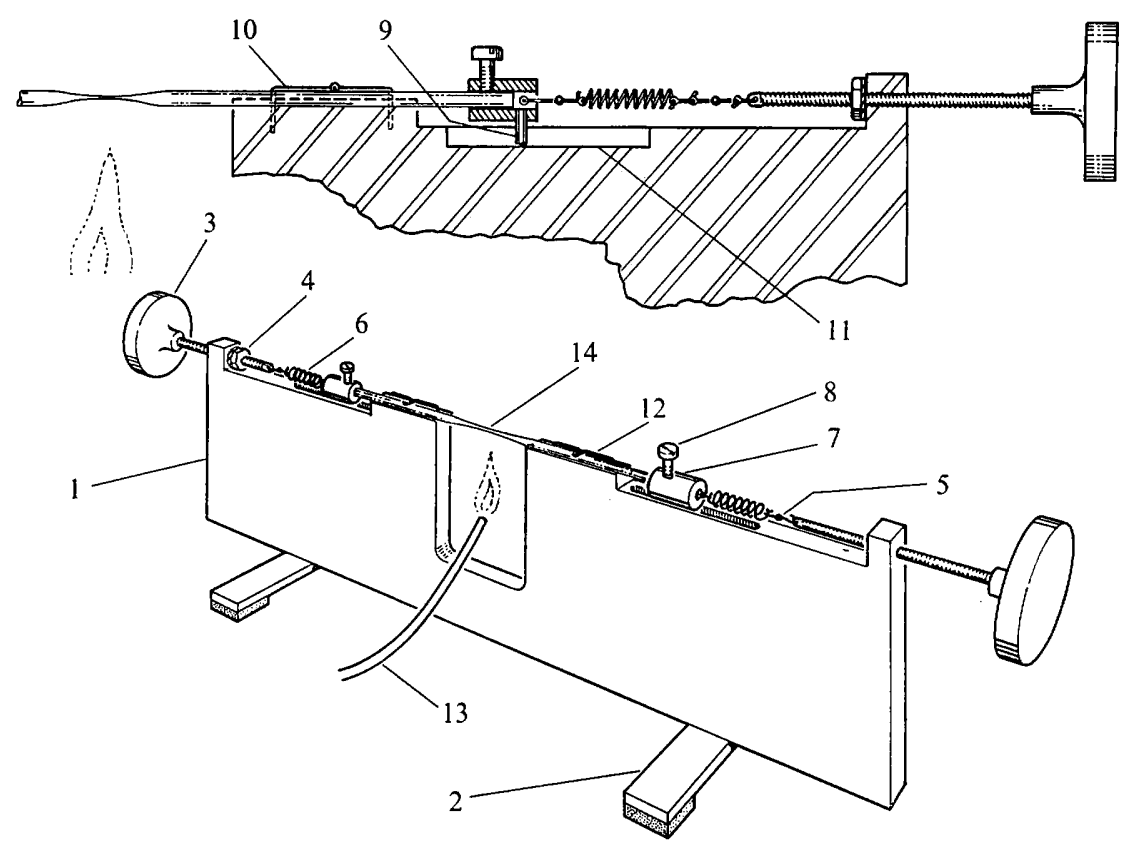

Fig. I. Gas microforge: (I) Alloy base; (2) foot; (3) brass studding and knob; (4) brass nut and locking washer; (5) fishing-line swivel; (6) spring; (7) connector; (8) nylon bolt; (9) peg; (I0) retaining clip; (I I) guide-channel; (I 2) V-groove; (I 3) pilot flame; (I4) glass-rod showing waist.

\section{DISCUSSION}

Needles which taper rapidly have greater rigidity and are best for micromanipulation. The degree of taper is very easily controlled by varying the number of turns of the tensioners, and with this forge it is possible to make needles with a tip diameter of $2 \mu \mathrm{m}$. The virtues of the forge are its simple design, ease of use and sensitivity. The key feature of the design is the use of fishing-line swivels. These allow the use of threaded tensioners which give a very delicate control of the force applied during needle-making.

A forge of this type can be made with little equipment and at very small cost. A prototype made from 'odds and ends' mounted on a wooden base was perfectly effective.

We are indebted to J. J. Hesling for his suggested use of fishing-line swivels and to Dr P. Knapp of the Institute's Design and Development section for his advice and help in making the forge.

\section{REFERENCE}

ThAYSEN, A. C. \& MorRIs, A. R. (1947). The preparation of microtools for the micromanipulator. Journal of General Microbiology I, 22 I-23I. 